\title{
Acute severe ulcerative colitis: management advice for internal medicine and emergency physicians-comment
}

\author{
Jayendra Shukla ${ }^{1} \cdot$ Anuraag Jena ${ }^{1} \cdot$ Vishal Sharma $^{1}$ D \\ Received: 31 March 2021 / Accepted: 3 April 2021 / Published online: 19 April 2021 \\ c) Società Italiana di Medicina Interna (SIMI) 2021
}

Keywords Inflammatory bowel disease - Ulcerative colitis · Acute severe colitis · Colectomy · Cyclosporine

\section{Dear Editor}

We have read with keen interest the recent thorough recent review by Rosiou et al. [1], regarding the management of acute severe ulcerative colitis (ASUC). We have certain comments concerning the use of cyclosporine for steroid-refractory ASUC. The authors correctly point to the potential risk of neurotoxicity. They suggest that the drug should be avoided in patients with cholesterol $(<115 \mathrm{mg} / \mathrm{dl})$ and hypomagnesemia $(<1.4 \mathrm{mg} /$ dl). Since only two agents, cyclosporine and infliximab, are currently standards of treatment in steroid refractory ASUC it is important not to deny the benefit of these drugs to eligible patients. In particular, cyclosporine is a cheap drug which can be used in most resource-constrained setting and therefore such recommendations should be based on evidence [2]. While hypomagnesemia is easily correctable, the correction of cholesterol levels is difficult and could potentially make a substantial group ineligible due to underlying malnutrition in these patients. If we closely look at the evidence, the risk of seizures has been noted with higher doses $(4 \mathrm{mg} / \mathrm{kg})$ [3]. The purported mechanism of cyclosporine-mediated neurotoxicity is related to higher free serum levels of this lipophilic drug in patients with low cholesterol levels and most reports are from setting of organ transplant where higher doses have been used [4]. We have been using the drug for induction of remission in steroid-refractory ASUC even in patients with lower cholesterol levels. Further, the traditional recommendation of not using cyclosporine in patients who are thiopurine refractory needs reconsideration. This is because newer therapies which may be not useful for induction of remission could still be used in the maintenance of remission. A bridge of calcineurin inhibitors to induce remission followed by vedolizumab maintenance has been reported

Vishal Sharma

sharma.vishal@pgimer.edu.in

1 Department of Gastroenterology, Postgraduate Institute of Medical Education and Research, Chandigarh, India and may be of value in certain situations where patients are not eligible for infliximab [5].

Evidence, not fear, should guide the use of cyclosporine in steroid refractory ASUC.

Funding None.

\section{Declarations}

Conflict of interest The author(s) declare that they have no conflict of interest.

Statements on human and animal rights The paper did not involve any human or animal research.

\section{References}

1. Rosiou K, Selinger CP (2021) Acute severe ulcerative colitis: management advice for internal medicine and emergency physicians. Intern Emerg Med. https://doi.org/10.1007/s11739-021-02704-0

2. Mishra S, Mandavdhare HS, Singh H et al (2020) Adjuvant use of combination of antibiotics in acute severe ulcerative colitis: a placebo controlled randomized trial. Expert Rev Anti Infect Ther. https://doi.org/10.1080/14787210.2021.1856656

3. Sternthal MB, Murphy SJ, George J et al (2008) Adverse events associated with the use of cyclosporine in patients with inflammatory bowel disease. Am J Gastroenterol 103:937-943. https:// doi.org/10.1111/j.1572-0241.2007.01718.x

4. Miller LW (1996) Cyclosporine-associated neurotoxicity. The need for a better guide for immunosuppressive therapy. Circulation 94:1209-1211. https://doi.org/10.1161/01.cir.94.6.1209

5. Ollech JE, Dwadasi S, Rai V et al (2020) Efficacy and safety of induction therapy with calcineurin inhibitors followed by vedolizumab maintenance in 71 patients with severe steroid-refractory ulcerative colitis. Aliment Pharmacol Ther 51:637-643. https:// doi.org/10.1111/apt.15616

Publisher's Note Springer Nature remains neutral with regard to jurisdictional claims in published maps and institutional affiliations. 